\title{
PRESENCE AND INOCULUM DENSITY OF Phytophthora IN, DIFFERENT COCONUT CULTIVARS IN DAVAO, PHILIPPINES
}

\author{
By \\ N.C.S.J. Bachiller ${ }^{1}$
}

\begin{abstract}
Phytophthora palmivora was present in the soil samples and organic debris deposited in leaf axil of coconut. Block planted with CAMT x MRD hybrid had the highest number of Phytophthora propagules (2.0) followed by CAMT (1.4) and KINGD (1.1). Aromatic and Catigan Green Dwarf had the least Phytopthora propagules.

Isolation of Phytophthora from the soil samples and organic debris from leaf axil was done through dilution plate and baiting method respectively using six month old Malayan Red Dwarf (MRD) nuts. Highest infection (100\%) on bait nuts was also obtained in CAMT x MRD hybrid 3.5 days after inoculation. Reisolation of Phytophthora from bait nuts gave positive results. Morphological characterization of the sporangium showed considerable variation in shapes and size.

More Phytophthora propagules was obtained in soil samples collected in areas previously planted with Malayan Yellow Dwarf x West African Tall (MAWA). Phytophthora palmivora is basically a soil borne pathogen but could easily be transported by wind and rainsplash, tent building ants and flying beetles.

\section{INTRODUCTION}

Understanding the nature of the disease and its causal organism is a must for the development of an effective and economical management system. Phytophthora bud rot of coconut, one of the earliest diseases discovered in the country was not systematically investigated till mid 80s when thousands of coconut palms were killed by the fungus. To date, scientists in the country are still trying to unravel the complex nature of this pathogen. This study report the basic researches ultimate for the development and effective application of a control strategy for the disease.
\end{abstract}

\section{METHODOLOGY}

\subsection{Collection of Samples}

\section{Organic Debris from Leaf Axil}

Eight blocks of coconut areas planted with various cultivars/hybrids were selected in the study. These blocks were planted with Aromatic Green Dwarf (AROGD), Catigan Green Dwarf (CATGD), Kinabalan Green Dwarf (KINGD), Malayan Red Dwarf (MRD), Camotes Tall (CAMT), CAMT x MRD, CATGD x LAGT and KAPGD x CAMT. Thirty six (36) randomly selected palms were sampled. All of the organic debris lodged on the leaf axils of every palm, starting from frond number 10 down to the last mature frond were taken, placed in a sterile plastic bag, and brought to the laboratory. Ten grams per sample were weighed for the Dilution Plate Method (DPM) and $250 \mathrm{~g}$ for the baiting method.

\section{Soil}

\footnotetext{
${ }^{1}$ Chief, Crop Protection Division, Philippine Coconut Authority, Davao Research Centre, Bago Oshiro, DavaoCity 8000, Philippines
} 
Thirty six randomly selected composite soil samples taken at 3-5 $\mathrm{cm}$ deep per sampling site in the eight coconut blocks in DRC were taken. Ten grams per sample was used for the Dilution Plate Method to establish the density of Phytophthora propagules and the $250 \mathrm{~g}$ for the baiting method to establish the presence of infectious propagules of the fungus.

\subsection{Method of Analysis}

\section{Dilution Plate Method}

Ten grams organic debris from leaf axil and soil sample from each palm were taken and mixed with $95 \mathrm{ml}$ sterile water blank in a dilution bottle. The mixture was placed in a reciprocating shaker for 15 minutes after which a series of dilution was made following the scheme below:

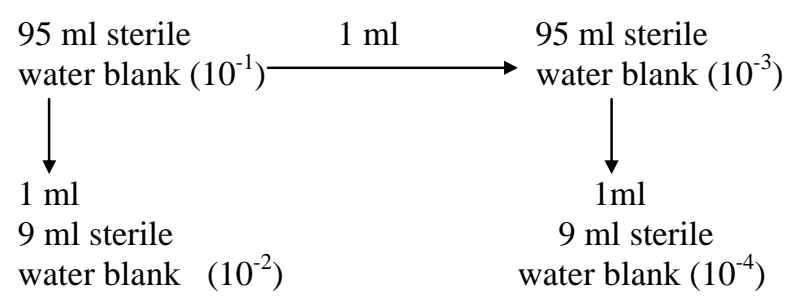

One milliliter each of the dilution per treatment was pipetted into sterile plates. Pre-cooled melted Carrot Agar medium was then poured into the inoculated plates which were gently rotated back and forth for uniform mixing of the suspension with the medium. The plates were incubated for 7 days and the number of colonies that grew per plate were counted. The fungi observed were then isolated and brought into pure cultures.

\section{Baiting Method}

Healthy six month old Malayan Red Dwarf (MRD) nuts were carefully collected and surface sterilized by $70 \%$ ethyl alcohol and then wiped dried with cotton. Ten pin pricks were made at the center of the equatorial portion of the nut using a sterile needle. Two hundred grams of soil and another of the organic matter per sample per variety were placed in a sterile plastic basin, after which two hundred fifty $\mathrm{ml}$ of sterile distilled water was added. A bait nut was then placed/mounted into each basins with the pricked portion slightly touching the surface of the water. The basin with the bait nuts were incubated under continuous light for seven days after which symptom of Phytophthora infection was observed.

\subsection{Isolation and Purification of $P$. palmivora}

Following the method described in the Philippine Council for Agriculture and Resources Research and Development (PCARRD) Manual (1980), the bait nuts manifesting symptoms of the disease were surface sterilized using $70 \%$ ethyl alcohol. From the advancing margins of the infected parts of the nuts, $5-\mathrm{mm}^{2}$ tissues were excised. The tissues were rinsed with ethyl alcohol, soaked in distilled water for 1 minute, then dried in a sterile filter paper. The tissue were planted in plated carrot agar (CA) medium and incubated under $24^{\circ} \mathrm{C}$ temperature. When growth of the pathogen was observed, the advancing portion of its mycelium was transferred and then maintain in CA slants to be used for further examination.

\subsection{Data gathered}

\section{Dilution Plate Method (DPM):}

The number of Phytophthora propagules per treatment was calculated using the formula: $\mathrm{B}=$ (A X D.F.)/W where B represents the number of propagules per gram of dry soil, A represents the average number of colonies on the best dilution, D.F. as the dilution factor, and W as the oven-dry weight of the soil sample (PCARRD Manual 1980). 
The fungi isolated were purified and identified to genus level using monograph on illustrate Genera of Imperfect Fungi (1972) by Barnett and Hunter.

\section{Baiting Method:}

Symptom development was observed fifteen days after incubation of bait nuts. Reisolation of the pathogen was done on positively infected nuts.

\section{Morphological Characteristic of P. palmivora}

P. palmivora isolated from the infected parts of the nuts were purified for sporangium measurement. Observation of sporangial length (L), breadth (B) pedicel length and papillation were measured using 50 sporangia of each isolate and the mean values were calculated.

\section{RESULTS AND DISCUSSION}

\section{Soil}

Phytophthora infectious propagules are present in areas planted with different cultivars as indicated by the positive infection on the bait nuts. Soil samples collected from areas planted with CAMT x MRD gave highest infection (100\%) on bait nuts 3.5 days after inoculation followed by KINGD and KAPGD x CAMT with 97.2 and $91.7 \%$ infection respectively on baits nuts 4.0 days after inoculation (Table 1a). Interestingly, Aromatic Green Dwarf (AGF) had the lowest nut infected (25\%) followed by Catigan Green Dwarf (CGD) (30.6\%) and CATGD x LAGT (38.8\%). Reisolation of Phytophthora from the bait nuts gave all positive result. As shown in Table 2a, the highest number of Phytopthora propagules from soil samples was recorded in CAMT x MRD hybrid. Bait nut was positively infected within 2.6 days after inoculation.

Table 1a. Nuts infected with Phytophthora palmivora in different cultivars/ hybrids (soil samples)

\begin{tabular}{|c|c|c|c|}
\hline \multirow{2}{*}{ Cultivars/hybrids } & \multirow{2}{*}{$\begin{array}{l}\text { Days after } \\
\text { inoculation }\end{array}$} & \multicolumn{2}{|c|}{ Nuts infected } \\
\hline & & Number $\%$ & \\
\hline \multicolumn{4}{|l|}{ A. Dwarf } \\
\hline AROGD & 12.0 & 9.0 & 25.0 \\
\hline CATGD & 111.5 & 11.0 & 30.6 \\
\hline MIRD & 9.5 & 17.0 & 47.2 \\
\hline KINGD & 4.0 & 35.0 & 97.2 \\
\hline \multicolumn{4}{|l|}{ B. Tall } \\
\hline CAMT & 7.0 & 25.0 & 69.4 \\
\hline \multicolumn{4}{|l|}{ C. Hybrid } \\
\hline CAMP x MRD & 3.5 & 36.0 & 100.0 \\
\hline KAPGDXCAMT & 4.0 & 33.0 & 91.7 \\
\hline CATGD x LAGT & 7.0 & 14.0 & 38.8 \\
\hline Mean & 6.5 & 26.0 & 73.4 \\
\hline
\end{tabular}

\section{Leaf Axil}

Organic matter from the leaf axil of different coconut cultivars stands harbor Phytophthora propagules as indicated by the positive infection on bait nuts. Percentage of nuts infected ranged from 5.6 to $38.9 \%$ (Table 1b). Highest infected bait nuts was observed again in CAMT x MRD (38.9\%) followed by Kinabalan Green Dwarf (KGD) (19.4\%), AGD and CGD had the lowest nut infection $(0 \%)$. 
Consistent with the report of Rillo and Paloma (1987) and Abad 1999, that yellow pigmented population (MRD) and CAMT x MRD are apparently more prone to Phytophthora infection than green pigmented population in this case AGD and CGD.

Table 1b. Nuts infected with Phytophthora palmivora in different cultivars/ hybrids (Leaf Axil)

\begin{tabular}{|c|c|c|c|}
\hline \multirow[t]{2}{*}{ Cultivars/hybrids } & \multirow[t]{2}{*}{ Days after inoculation } & \multicolumn{2}{|c|}{ Nuts infected } \\
\hline & & Numbers & $\%$ \\
\hline A. Dwarf & & & \\
\hline AROGD & 15.0 & 0.0 & 0.0 \\
\hline CATGD & 15.0 & 0.0 & 0.0 \\
\hline MIRD & 14.5 & 2.0 & 5.6 \\
\hline KINGD & 12.5 & 7.0 & $\overline{19.4}$ \\
\hline \multicolumn{4}{|l|}{ B. Tall } \\
\hline CAMT & 13.0 & 5.0 & 13.9 \\
\hline \multicolumn{4}{|l|}{ C. Hybrid } \\
\hline CAMP x MRD & 10.5 & 14.0 & 38.9 \\
\hline KAPGDXCAMT & 13.5 & 4.0 & 11.1 \\
\hline CATGD x LAGT & 15.0 & 2.0 & 5.6 \\
\hline Mean & 13.0 & 5.5 & 15.5 \\
\hline
\end{tabular}

Highest Phytophthora propagules was observed in $10^{-2}$ dilution in organic debris from leaf axil collected in CAMT x MRD hybrid (Table 2b). This suggests that Phytophthora isolate from CAMT x MRD hybrid is more virulent as compared with other isolates. This confirm report by Poliquit \& Abad (1999) that Phytophthora has pathogenic variability in terms of aggressiveness to colonize the hosts. Likewise, more $P$. palmivora propagules was observed in areas previously planted with Malayan Yellow Dwarf (MYD) x West African Tall (WAT) as in the case of coconut cultivars/hybrids planted with CAMT, CAMT x MRD, KAPGD x CAMT and CATGD x LAGT. Consistent with the report of Guest (2002) that Phytopthora palmivora basically a soil-borne pathogen but well adapted to infect aerial part of the plant such as coconut bud rot \& fruit rot. Phytophthora inoculum moves from the soil to the canopy as a result of human activity, rainsplash and flying beetles.

Table 2a. Number of Phytophthora propagules $\left(10^{-2}\right)$ and infected nuts in different cultivars/ hybrids (soil samples)

\begin{tabular}{|c|c|c|c|c|}
\hline \multirow{2}{*}{ Cultivars/hybrids } & \multirow{2}{*}{ Days after inoculation } & \multirow{2}{*}{ Number of propagules } & \multicolumn{2}{|c|}{ Nuts infected } \\
\hline & & & \multicolumn{2}{|c|}{ Numbers $\%$} \\
\hline \multicolumn{5}{|l|}{ A. Dwarf } \\
\hline AROGD & 15.0 & 0.0 & 9.0 & 25.0 \\
\hline CATGD & 15.0 & 0.0 & 11.0 & 30.6 \\
\hline MIRD & 14.0 & 2.0 & 17.0 & 47.2 \\
\hline KINGD & 13.0 & 29.0 & 35.0 & 97.2 \\
\hline \multicolumn{5}{|l|}{ B. Tall } \\
\hline CAMT & 14.0 & 34.0 & 25.0 & 69.4 \\
\hline \multicolumn{5}{|l|}{ C. Hybrid } \\
\hline CAMP x MRD & 2.6 & 36.0 & 36.0 & 100.0 \\
\hline KAPGDXCAMT & 13.0 & 7.0 & 33.0 & 91.7 \\
\hline CATGD x LAGT & 14.0 & 2.0 & 14.0 & 38.8 \\
\hline
\end{tabular}


Highest number of progagules was observed again in CAMT x MRD hybrid (1.5) followed by CAMT (1.2). AGD and CGD consistently recorded zero propagules of Phytophthora (Table 2b).

Among the four PKI cultivars/hybrids Phytophthora propagules was highest in CAMT x MRD, indicate apparenting susceptibility of this hybrid because of MRD parentage (Concibido 1990).

Table 2b. Number of Phytophthora propagules $\left(10^{-2}\right)$ and infected nuts in different cultivars/ hybrids (Leaf Axil)

\begin{tabular}{|c|c|c|c|c|}
\hline \multirow{2}{*}{ Cultivars/ hybrids } & \multirow{2}{*}{ Days after inoculation } & \multirow{2}{*}{ Number of propagules } & \multicolumn{2}{|c|}{ Nuts infected } \\
\hline & & & \multicolumn{2}{|c|}{ Numbers \% } \\
\hline \multicolumn{5}{|l|}{ A. Dwarf } \\
\hline AROGD & 15.0 & 0.0 & 0.0 & 0.0 \\
\hline CATGD & 15.0 & 0.0 & 0.0 & 0.0 \\
\hline MIRD & 15.0 & 0.0 & 0.0 & 0.0 \\
\hline KINGD & 10.0 & 1.0 & 15.0 & 41.7 \\
\hline \multicolumn{5}{|l|}{ B. Tall } \\
\hline CAMT & 5.5 & 1.2 & 26.0 & 72.2 \\
\hline \multicolumn{5}{|l|}{ C. Hybrid } \\
\hline CAMP x MRD & 2.5 & 1.5 & 35.0 & 97.2 \\
\hline KAPGDXCAMT & 6.0 & 1.0 & 24.0 & 66.7 \\
\hline CATGD x LAGT & 15.0 & 0.0 & 0.0 & 38.8 \\
\hline
\end{tabular}

\section{Baiting Method}

The presence of $P$. palmivora in leaf axil and soil as determined through baiting is shown in Table 3. All soil samples and organic debris in leaf axil were positive for P. palmivora except from AROGD and CATGD. After 4 days of incubation under continuous light, lesions around the pricked portion of the bait nuts were observed (Fig. 1). This symptom is typical of nuts that are positively infected with $P$. palmivora. Reisolation of the pathogen in Carrot Agar (CA) and microscopic examination of the isolates were then made confirmed the mycelial growth is that identity of $P$. palmivora.

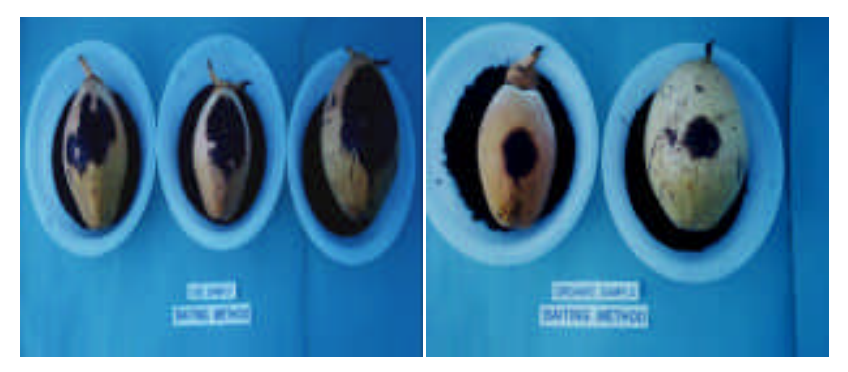

Fig. 1. Lessions caused by Phytophthora palmivora in the bait nuts, 4 days after incubation under continuous light

\section{Dilution Plate Method}

Leaf axils of the coconut palms sampled in the study were found to have mycoflora associated with the organic matter deposited thereon. The list of the seven fungi collected from the samples and identified up to its genus level (Table 4). The fungi include Aspergillus sp., Penicillium A, B, Pestalotiopsis sp., Trichoderma species, two unidentified fungal isolates and Phytophthora palmivora. The identify of the two fungi could not be pursued because they did not sporulate in vitro. Of the seven fungi isolated from soil samples, only six were present in the organic debris from leaf axil, namely, Aspergillus sp., Penicillium sp. A, Pestalotiopsis sp., Phytophthora palmivora and unidentified fungi (A \& B isolates). There were many kinds of fungi isolated in soil than in organic debris, with the presumption that some fungi do not favorably coexist with $P$. palmivora due to competition and antagonism. On the other hand, the 
presence of some fungi along with the pathogen suggest that these fungi have capacity to compete and therefore coexist with P. palmivora. It is also possible that they have different niches or mode of survival, thus not adversely affecting each other.

Table 4. Various fungi isolated from organic matter in leaf axil and soil samples

\begin{tabular}{|l|c|c|}
\hline \multirow{2}{*}{ Fungi } & \multicolumn{2}{|c|}{ Occurrence } \\
\cline { 2 - 3 } & Leaf axil & Soil sample \\
\hline Aspwergillus $s p$. & + & + \\
\hline Penicillium $s p$. A & + & + \\
\hline Penicillium $s p$. B & - & + \\
\hline Pestalotiopsis sp. & + & + \\
\hline Phytoptthora palmivora & + & + \\
\hline Trichoderm sp. & - & + \\
\hline Unidentified fungal isolate A & + & + \\
\hline Unidentified fungal isolate B & + & + \\
\hline
\end{tabular}

+ present - absent

The occurrence of the various fungi obtained from the soil and organic matter are reflected in Table 4. The collection of Pestalotiopsis sp., the causal organism of leaf spot/blight of coconut although a disease of lesser economic importance than Phytophthora bud rot, deserves some attention. Its presence points to leaf axil as source of pathogen propagules that should be considered in crafting coconut disease management schemes.

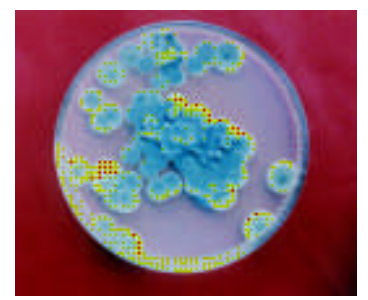
isolated from leaf axil \& soil isolates from eight blocks (Table 5). The isolates observed produced papillae and caducous sporangia Waterhouse (1974) reported that these isolates were considered caducous if the majority of their sporangia readily detached from sporangiophores and did not have frayed raptures at their stalk (pedicel) bases. Most of the sporangia observed were borne terminally either a simple sympodia or on irregular sporangiospores. The eight isolates produced ovoid, ellipsoid, obpyriform type of sporangia with a round or slightly tapering based and an occluded short pedicel.
Fig 2. Pecillium sp. A, samples showing light green colonies cultured on Potato Dextrose
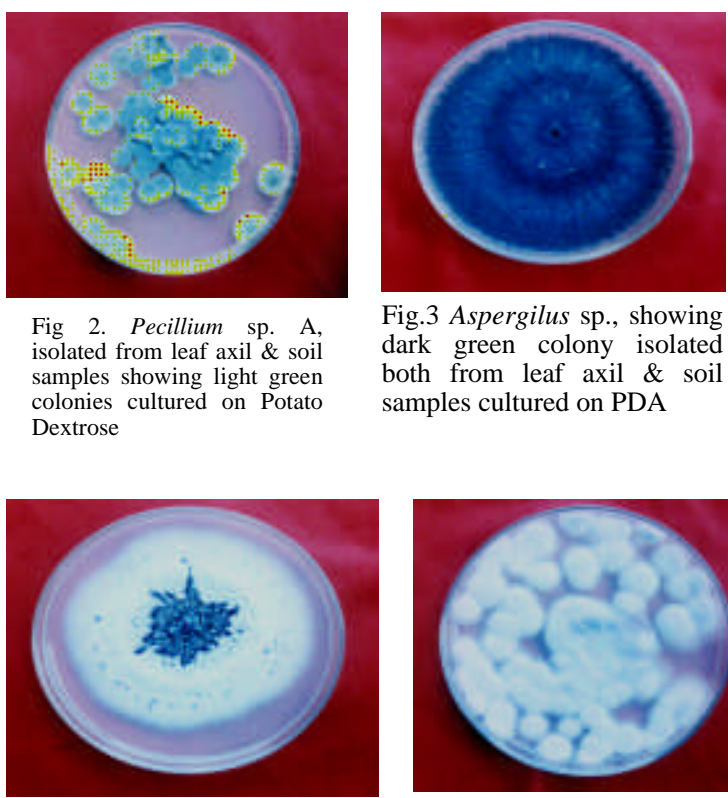

Fig.3 Aspergilus sp., showing dark green colony isolated both from leaf axil \& soil samples cultured on PDA

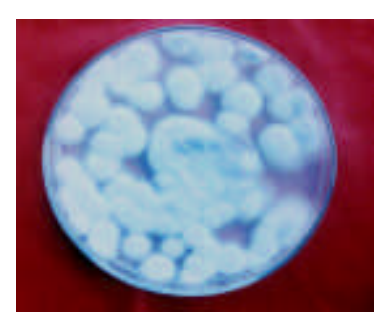

on medium.

Fig.4.Colony of Pestalotiopsis sp., Isolated from leaf axil samples cultured on isolated from leaf axil and soil samples

\section{Morphological Characteristic of Phitophora}

Eight Phytophthora (4 Dwarfs, 1 tall \& 3 hybrids) isolates were purified and measured for the sporangial dimension. Considerable variation was observed in sporangial shapes and sizes among the 
Table 5. Morphological characteristic/measurement of Phytophthora sporangia isolated from different cultivars (soil sample)

\begin{tabular}{|l|l|l|l|l|l|l|}
\hline \multirow{2}{*}{ Cultivars/hybrids } & \multicolumn{7}{|c|}{ Sporangium Dimension (u ) } \\
\cline { 2 - 8 } & Leng-hth & Brea-dth & \multicolumn{2}{|c|}{ Pedicel } & \multicolumn{2}{c|}{ Papila } \\
\hline A. Dwarf & & & & & & \\
\hline AROGD & 0.09 & 0.07 & 0.97 & 0.92 & 0.12 & 0.16 \\
\hline CATGD & 0.09 & 0.08 & 1.19 & 0.76 & 0.10 & 0.17 \\
\hline MIRD & 0.08 & 0.08 & 1.05 & 0.69 & 0.12 & 0.18 \\
\hline KINGD & 0.09 & 0.08 & 1.03 & 0.71 & 0.11 & 0.17 \\
\hline B. Tall & & & & & & \\
\hline CAMT x & 0.09 & 0.08 & 1.06 & 0.72 & 0.11 & 0.17 \\
\hline C. Hybrids & & & & & & \\
\hline CAMT x MRD & 0.09 & 0.08 & 1.01 & 0.78 & 0.12 & 0.18 \\
\hline KAPGD x CAMT & 0.09 & 0.08 & 1.08 & 0.72 & 0.18 & 0.18 \\
\hline CATGD x LAGT & 0.09 & 0.07 & 0.97 & 0.72 & 0.16 & 0.16 \\
\hline
\end{tabular}

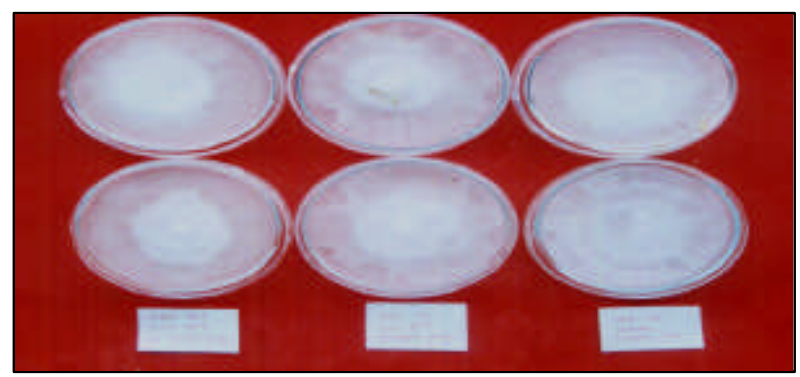

Fig. 6. Phytophthora palmivora showing radiate type of mycelial colony isolated both from the leaf axil and soil samples

\section{CONCLUSION}

Presence of Phytophthora palmivora was observed both in soil and coconut leaf axil microhabitat. This could give way to improved disease management measures in coconut and may offer awareness for further detailed studies. Phytophthora is basically a soil-borne pathogen, although species including $P$. palmivora are well adopted to attack aerial parts of plants causing disease such as coconut bud rot, coconut fruit rot, durian canker, durian leaf blight, and fruit rot. Palmivora inoculum moves from the soil into the canopy as a result of human activity, contaminated farm implements, rainsplash, tent building ants, flying beetles and different mammals. Once in the canopy, secondary inoculum spread Phytophthora to infect coconut bud and fruit rot, rainsplash, ants, flying beetles and mammals.

Density of Phytophthora propgules in the soil and leaf axil are determind. Once bud rot is observed in an area, immediate removal by cutting and burning of the infected palms is recommended to ensure the reduction of inoculums of Phytophthora. Likewise, other important pest (e.g. rhinoceros beetle) will have no habitable breeding place for multiplication and thus, outbreak of the pest can be prevented.

Coconut cultivars (e.g. green pigmented population) was observed to be least susceptible to bud rot and fruit rot. 


\section{REFERENCES}

Abad, R.G. (1985). Management of coconut diseases. Philippine J. Coco. Studies 17: pp.87-92.

Abad, R.G. Condibido, E.C., Manohar, and Poliquit, E.S. (1999). Studies on the effect of farm sanitation and fungicide treatment on the incidence of Phytophthora disease of coconut. Philippine J. Coco. Studies 24(2): pp.6-11.

Barnett, H.L. and Hunter, B.B. (1972). Illustrated general of imperfect fungi. $3^{\text {rd }}$ Ed. Burgess Publishing Company. Minnesota, 180p.

Bennet, C.P.A., Robot, D. Sitepu and Lolong, A. (1986). Pathogencity of Phytophthora palmivora (Butl.) Butl. causing premature nutfall disease of coconut (Cocos nucifera L.). Indonesian Coco. Sci. 2(2) : pp.59-70.

Brasier, C.M. and Griffin, M.J. (1979). Taxonomy of Phytophthora palmivora on cacao. Trans. British Mycol. Soc. (72): pp.11-143.

Concibido, E.C. (1990). Distribution and comparative studies of Phytophthora disease of coconut (Cocos nucifera L.) in the Philippines. Unpublished M.S. Thesis, UPLB, 74p.

Guest, D. (2002). Understanding disease cycles of Phytophthora in the tropics. Proceeding on the Workshop on Phytophthora in Southeast Asia. Chaing Mai, Thailand, 8-12 Nov. 2002

Poliquit, E.S. and Abad, R.G. (1999). Studies on the pathogencity and host range of coconut, durian and cacao Phytophthora isolates under controlled conditions. Philippine J. Coco. Studies 24(2): pp. 1-5.

Quillec, G. and Renard, J.L. (1984). Phytophthora rot of coconut, Oleagineux 39(3): pp.143-145.

Reinking, O.A. (1923). Comparative study of Phytophthora faberi on coconut and cacao in the Philippine Island. J. Agric. Res. 25: pp.67-264.

Rillo, E.P. and Paloma, M.B.F. (1989). Reaction of some coconut cultivars and hybrids to Phytophthora disease. Philippine J. Coco. Studies 14(1): pp.2-6.

Waterhouse, G.M. (1974). Phytophthora palmivora and some related species. In Phytophthora diseases cocoa, (Ed.) P.H. Gregory), pp.51-70. Longman. New York.

Concibido, E.C. (1990). Distribution and comparative studies of Phytophthora disease of coconut (Cocos nucifera L.) in the Philippines. Unpublished M.S. Thesis, UPLB, 74p.

Guest, D. (2002). Understanding disease cycles of Phytophthora in the tropics. Proceeding on the Workshop on Phytophthora in Southeast Asia. Chiang Mai, Thailand, 8-12 Nov. 2002

Poliquit, E.S. and Abad, R.G. (1999). Studies on the pathogencity and host range of coconut, durian and cacao Phytophthora isolates under controlled conditions. Philippine J. Coco. Studies 24(2) pp. 1-5.

Quiliec, G. and J.L. Renard (1984). Phytophthora rot of coconut, Oleagineux 39(3): pp.143-145.

Reinking, O.A. (1923). Comparative study of Phytophthora faberi on coconut and cacao in the Philippine Island. J. Agric. Res. 25: pp.167-264.

Rillo, E.P. and Paloma, M.B.F. (1989). Reaction of some coconut cultivars and hybrids to Phytophthora disease. Philippine J. Coconut Studies 14(1): pp.2-6.

Waterhouse, G.M. (1974). Phytophthora palmivora and some related species. In Phytophthora diseases cocoa, (Ed.) P.H. Gregory), pp.51-70. Longman. New York. 